\title{
Cooperative Control to Enhance the Frequency Stability of Islanded Microgrids with DFIG-SMES
}

\author{
Wei Gu ${ }^{1, *}$, Wei Liu ${ }^{1}$, Zhi Wu ${ }^{1}$, Bo Zhao ${ }^{2}$ and Wu Chen ${ }^{1}$
}

1 School of Electrical Engineering, Southeast University, Nanjing 210096, China; E-Mails: 1wsword@hotmail.com (W.L.); wuzhilxy@163.com (Z.W.); chenwu@seu.edu.cn (W.C.)

Zhejiang Electric Power Test and Research Institute, Hangzhou 310000, China;

E-Mail: zhaobozju@163.com

* Author to whom correspondence should be addressed; E-Mail: wgu@seu.edu.cn;

Tel.: +86-138-1400-5169; Fax: +86-25-8379-1696.

Received: 6 May 2013; in revised form: 13 July 2013 / Accepted: 18 July 2013 /

Published: 6 August 2013

\begin{abstract}
The issue of frequency stability of microgrids under islanded operation mode and mode transfer has attracted particular attention recently. In this paper, a cooperative frequency control method, which consists of a microgrid central control (MGCC) and microgrid local control (MGLC), is proposed to achieve a seamless transfer from grid-connected to islanded mode, and hence increase the frequency stability of islanded microgrids during both primary and secondary frequency control. A power deficiency prediction and distribution method is proposed in MGCC to effectively distribute and utilize the power and loads, and accomplish the cooperative control of all microgrid units. With regards to MGLC, a Hopfield fuzzy neural network control (HFNNC) is applied to make the corresponding frequency control of DFIG-SMES more adaptive. Meanwhile a state of capacity (SOC) control is utilized in battery energy storage (BES) to extend battery life. Simulation results indicate that the proposed frequency control approach can maintain the frequency stability of islanded microgrids even in emergency conditions.
\end{abstract}

Keywords: cooperative control; DFIG-SMES; microgrid central control (MGCC); microgrid local control (MGLC); Hopfield fuzzy neural network control (HFNNC); state of charge (SOC) 


\section{Introduction}

The requirements to alleviate the energy crisis and the concerns over the potentially adverse effects on the environment have led to the rapid expansion of microgrid technology in recent years $[1,2]$. A microgrid including distributed generators [DG, such as double fed wind turbines (DFIGs), photovoltaics (PVs), and microturbines (MTs), etc.], energy storage [ES, such as superconducting magnetic energy storage (SMES), battery energy storage (BES), etc.] and loads, provides a new paradigm for local power supply [3].

Microgrids can be operated in grid-connected mode or islanded mode [4]. In grid-connected mode, the frequency is controlled and maintained within a tight range by the main grid. On the other hand, in islanded mode, the frequency control is achieved by the coordination of available DGs and ESs. An islanded microgrid is an autonomous power system with a small equivalent inertia, which makes its frequency control more difficult than for conventional grids. Due to the operation mode transfer and intermittent characteristics of some micro-generators, frequency deviation caused by active power deficiency often occurs in islanded microgrids [5]. During the grid-disconnect operation, when a fault occurs the power balance between supply and demand does not match at the moment. As a result, the frequency of the microgrid will fluctuate, and the system frequency may change rapidly due to the low inertia present in the microgrid and even experience a blackout unless there is an adequate available spinning reserve for balancing the microgrid [6-8].

Previously, to overcome this limitation the local control strategy of ESs (including BES, SMES, etc.) was considered as one of the main solutions for frequency stabilization of microgrids by absorbing or injecting instantaneous power. Recently, driven by the urgent needs to realize a more efficient smart grid, the SOC index of ES is taken into consideration to reduce the economical costs and extend the service life of ES $[9,10]$. Reference [11] presents a method with additional charging and SOC limits for the dimensioning of a BES to provide primary frequency support. Subsequently, power managements of DGs (including MT, DFIG, etc.) also play an important role in maintaining frequency stability and regulating the microgrid to a new balanced state [12]. It has to be noted that DFIG can effectively support system frequency by auxiliary frequency control. Through the auxiliary control DFIG can release rotor kinetic energy to the power system and share sudden changes in power requirements. In addition, DFIG can operate in a power reserved mode when the wind energy is sufficient, hence it can increase the power output and make up for the power shortage as a synchronous generator [13-15]. Moreover, DFIG operates linked with SMES and not only can achieve a smooth power output for a wind generator, but also can give more effective system frequency support $[16,17]$. Eventually, the two layered frequency control scheme of a microgrid is one of the main issues in islanded operation mode [18,19]. In [20], a cooperative control strategy of microsources and an energy storage system during islanded operation is presented and evaluated by simulation and experiment. This scheme utilizes stored energy to make up the power deficiency in primary frequency control. In addition, the secondary control of DGs regulates the power output of ESs back to zero. A hierarchical control system is proposed in [21] based on DG converters for robust microgrid operation and seamless transfer between grid-connected and isolated modes. Microgrida can operate in a stable way during islanded mode even though the load is changed suddenly. In conclusion, the cooperative 
frequency control scheme with advanced local control of DGs and ESs is needed to effectively achieve the goal in islanded operation.

In this paper, the frequency control of microgrids is implemented by both the primary and secondary frequency control as the conventional power systems [22]. The frequency control concepts, including the primary and secondary frequency controls are introduced to stabilize the frequency of microgrid in [23]. For the inverter-based distributed unit without speed governor and spinning inertia, the primary and secondary frequency controls are achieved by ESs and DGs which have different response times. The primary frequency control acts in ES is a deviation adjustment, while the secondary frequency control has zero error output adjustment by control of DGs $[21,23]$. Therefore the objectives of the primary and secondary frequency control are set respectively, and the objective of the primary frequency is to maintain the frequency stability of the microgrid quickly using the power stored in ESs and RKE of DFIGs [13,15]. Ranked in the secondary frequency control, two objectives are designed through the power outputs control of DGs, one is to predict and distribute the power deficiency during the primary frequency control, and the other is to regulate the frequency to its rated value.

Accordingly this paper addresses a two-layer cooperative control strategy, which consists of a microgrid central control (MGCC) and microgrid local control (MGLC), to achieve a seamless transfer from grid-connected to islanded mode, and increase the frequency stability of islanded microgrids. In MGCC, a power deficiency prediction and distribution method based on rate of change of frequency (ROCOF) and equivalent inertia is proposed to achieve cooperative control and effectively utilize the power and load. With regard to MGLC, a Hopfield fuzzy neural network control (HFNNC) is proposed in a double fed induction generator and superconducting magnetic energy storage (DFIG-SMES) module to make the corresponding frequency control approach more adaptive. Meanwhile a SOC control is utilized for the battery energy system (BES) to extend battery life. To evaluate the proposed control strategy, a dynamic simulation system was developed based on PSCAD/EMTDC. The control strategies, including MGCC and MGLC (HFNNC and SOC), were realized based on PSCAD/EMTDC and MATLAB associated technologies. Simulation results were presented and discussed to illustrate the dynamic performance of the proposed control strategies in islanded operation.

The remainder of the paper is organized as follows: Section 2 gives a brief introduction on the frequency control of islanded microgrids with a DFIG-SMES module and BES; Section 3 introduces the proposed cooperative frequency control strategy for autonomous microgrid; the proposed method is illustrated and investigated with a simulation system in Section 4; finally, the conclusions are duly drawn.

\section{Background}

\subsection{Microgrid Modeling}

A representative microgrid usually comprises DGs (MT, DFIG, and PV) as well as ESs (BES, SMES etc), in addition to loads. DGs fulfill the stable operation needs of a facility, while the ESs ensure the balance between energy generation and consumption, especially during islanded operation, and analogously act as the spinning reserve of large generators in the conventional grid. The microgrid is connected to the main grid at the point of common coupling (PCC), and operates in parallel with a 
utility grid under normal situations. When a fault occurs in the upstream grid, the microgrid disconnects from the main grid, however, and transfers into islanded operation mode [24].

The modeling of the distributed energy resources (DERs), including MT, PV, DFIG-SMES, and BES, in addition the inverter control strategy applied in this paper are all discussed as follows:

(a) MT: MTs are simple-cycle gas turbines with outputs ranging typically from about $25 \mathrm{~kW}$ to $500 \mathrm{~kW}$ and designed to operate for long periods with less maintenance. They can be used for load requirements, peak shaving and cogeneration applications. MTs may be single shaft or split-shaft units, the single shaft MT which used in this paper require an AC/DC/AC converter for grid connection $[5,6]$. In considering of the operation characteristics of MT in microgrid and convenience of the simulation, a typical synchronous generator model in PSCAD/EMTDC is applied to represent the MT [21].

(b) PV: PV panels do not require fuel to operate and produce zero noise and pollutant emissions. For grid connection, PVs need DC/AC inverters. The main disadvantage of PVs is that their operation depends on sunlight availability. Usually, a PV is operated in maximum power point tracking (MPPT) mode in order to use the sunlight more efficiently [7,8].

(c) DFIG-SMES: The structure of a DFIG-SMES system is shown in Figure 1. The SMES module is linked to the DFIG bus side, so it can absorb or release power to adjust the output power of DFIG to improve the voltage and frequency stability of the system. The current source control (CSC) topological structure is applied to connect the SMES to DFIG-SMES system [25]. As shown in Figure 1, both the resistance and voltage offset of the transformer are ignored, then the modeling of DFIG-SMES system can be described as follows:

Figure 1. DFIG-SMES system.

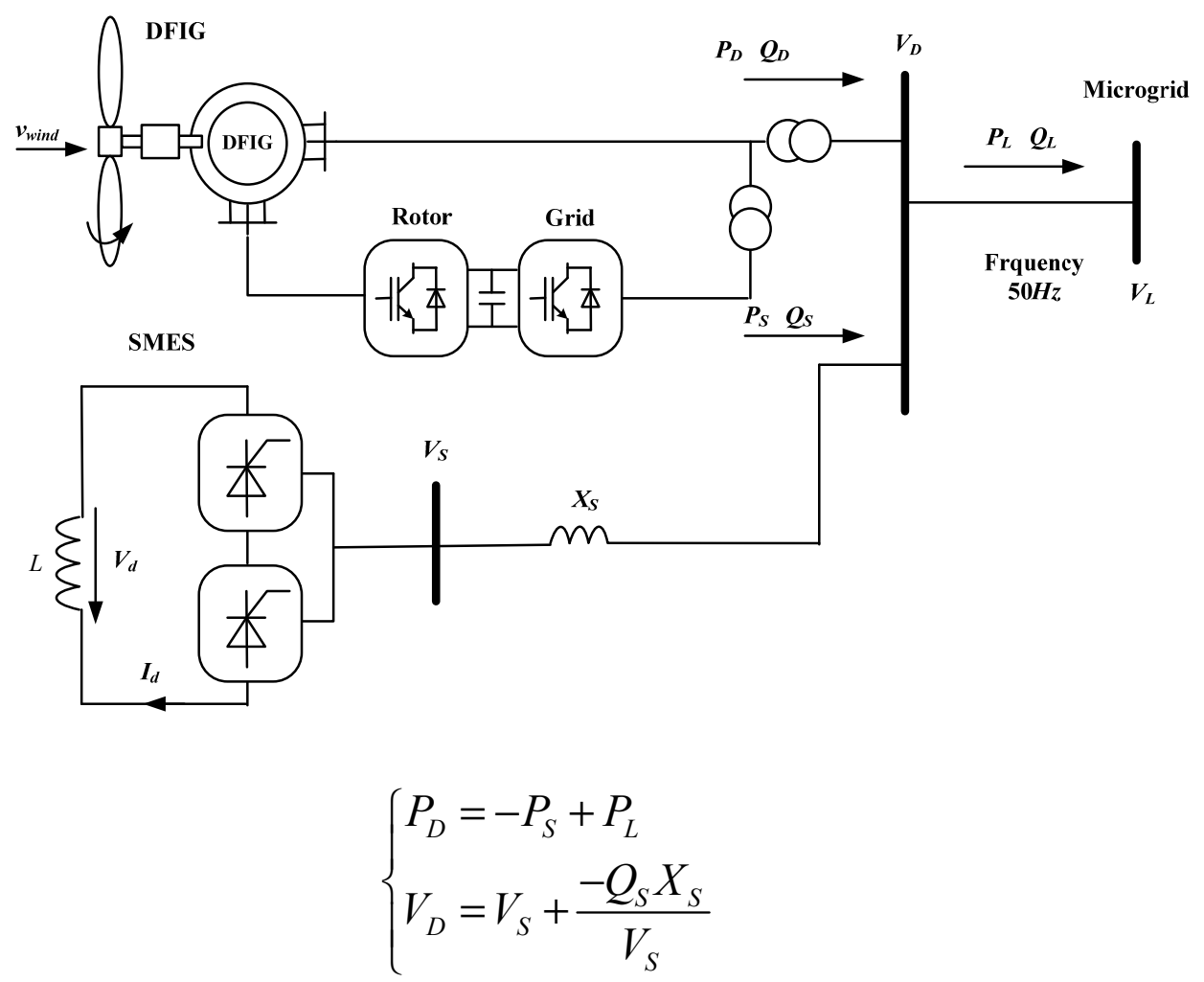


The power exchange of SMES-DFIG system can be expressed as:

$$
P_{S}+j Q_{S}=V_{D} I_{S}^{*}
$$

where $P_{S}$ is the output active power of SMES; and $Q_{S}$ is the reactive power of SMES; $I_{S}$ is the injection current; $V_{D}$ is the export voltage of DFIG.

Based on the power exchange of DFIG and SMES which is expressed as Equation (2), the main control strategies of DFIG-SMES for frequency support are rotor kinetic energy control (RKEC) and reserved power control (RPC) of DFIG, respectively, as well as the active power control of SMES. The principles of these three control strategies are briefly introduced as follows.

RKEC takes advantages of RKE of DFIG to optimize the system frequency control characteristics. Through RKEC the DFIG can release the RKE to alleviate a reduced frequency rate and improve the frequency control ability of the DFIG during the frequency decrease. Moreover RPC of DFIG is essentially a pitch angle control strategy, which aims at providing frequency support by releasing the reserved power during frequency deviation. The reserved power is released by changing the pitch angle of the system [13-15,25].

SMES can further improve DFIG-SMES system frequency control ability. The active power output of SMES is controlled during frequency deviation, then the energy stored in SMES can be released to alleviate the system pressure when the frequency is offset from frequency rating [16,17,26,27].

(d) BES: The BES model is presented based on the double-well model, the right side well is used to mark the available charge, while the left is for bound charge [28]. Among them, the available charge provides electric power to system, and the bound charges transfer into the available charge at a certain speed. The process can be described as follows:

$$
\left\{\begin{array}{l}
\frac{d y_{1}}{d t}=-i(t)+k\left(\frac{y_{1}}{c}-\frac{y_{2}}{1-c}\right) \\
\frac{d y_{2}}{d t}=-k\left(\frac{y_{1}}{c}-\frac{y_{2}}{1-c}\right)
\end{array}\right.
$$

where $c$ is the proportion of available charge of BES; $y_{1}, y_{2}$ are the capacities of available charge and bound charge, respectively; $k$ is the rate of bound charge change into available charge. The equations above are differential equations expressing the transformation from $y_{1}$ to $y_{2}$, when $i(t)$ is constant, that is $i(t)=I$, Equation (3) can be derived by Laplace transformation as:

$$
\left\{\begin{array}{l}
y_{1}(t)=y_{1,0} e^{-k^{\prime} t}+\frac{\left(y_{0} k^{\prime} c-I\right)\left(1-e^{-k^{\prime} t}\right)}{k^{\prime}}-\frac{I c\left(k^{\prime} t-1-e^{-k^{\prime} t}\right)}{k^{\prime}} \\
y_{2}(t)=y_{2,0} e^{-k^{\prime} t}+y_{0}(1-c)\left(1-e^{-k^{\prime} t}\right)-\frac{I(1-c)\left(k^{\prime} t-1+e^{-k^{\prime} t}\right)}{k^{\prime}}
\end{array}\right.
$$

where, $k^{\prime}=k /[c(1-c)] ; y_{1,0}$ and $y_{2,0}$ are the available charge and bound charge at the initial time $t=0$; and $y_{0}=y_{1,0}+y_{2,0}$. SOC is defined as the available capacity in a BES, which is expressed as a percentage of the estimated rated capacity [29]. Assume that the terminal voltage of battery bank $V(\mathrm{~V})$ and the maximum capacity of battery $C_{B E S_{-} \max }$ (mostly expressed in ampere-hour, Ah) are constant, so 
once the power of the battery is determined, the current and charge in the battery also can be calculated. Then the SOC can be calculated by Equation (5):

$$
\operatorname{SOC}(\%)=\frac{y_{0} \cdot I}{C_{B E S \_ \text {max }}} \times 100 \%
$$

(e) Inverter Control: There are two kinds of control strategies applied in this paper for operating an inverter, separately named PQ control and VF control [7,8]. The mode transfer between PQ and VF is controlled by the MGCC. For PQ control, the inverter is utilized to supply a preset active and reactive power according to the power references distributed by MGCC. In VF control mode, the inverter is controlled to feed the load with pre-defined values for maintaining the frequency and voltage of the islanded microgrid at the rated value.

\subsection{Frequency Control Structure of Microgrid}

Typically, the microgrid has a two-layered hierarchical control structure, as shown in Figure 2. The mentioned two layers are MGCC (microgrid central control) and MGLC (microgrid local control), respectively.

Figure 2. Two layered frequency control framework.

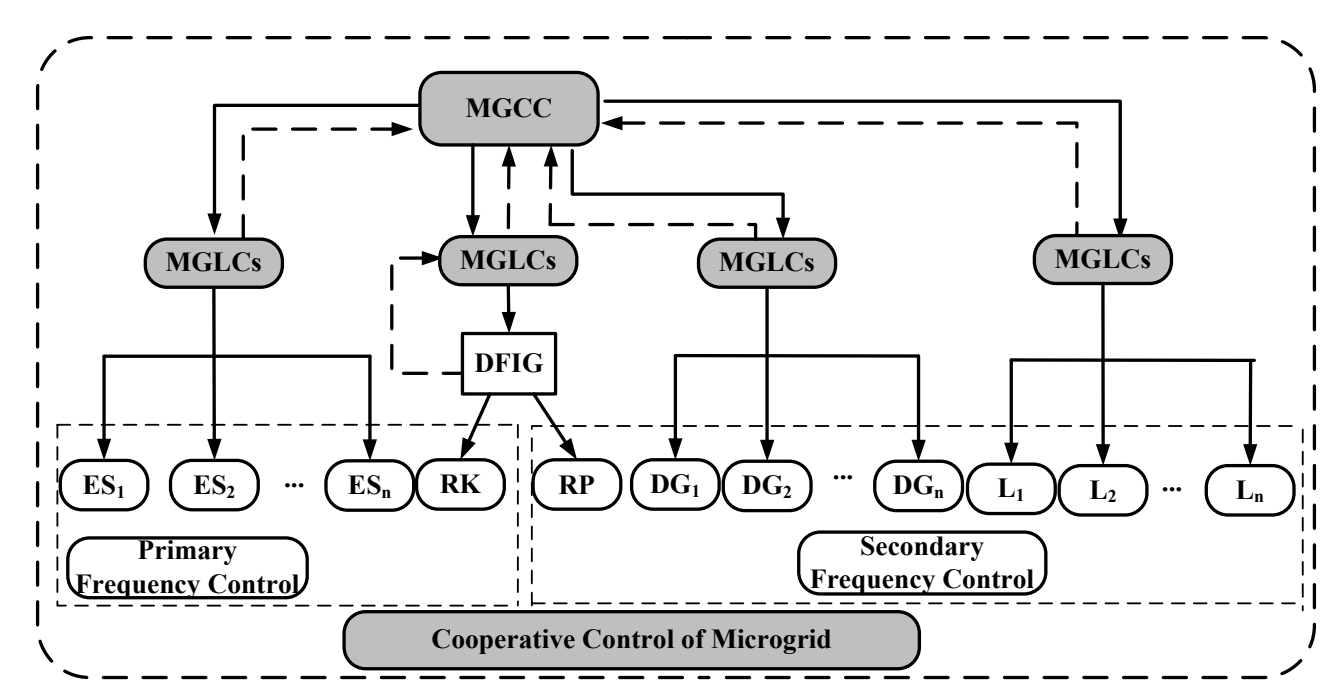

It can be seen from the above Figure 2 that, as a centralized controller, the MGCC of the microgrid captures the global information and deals with management functions, such as disconnection and resynchronization of the microgrid. In addition, the MGCC is responsible for the supervisory control of DGs and ESs. Based on the collected global information, the MGCC generates power output references and provides them to the MGLCs. The MGLCs which locate at each DGs and ESs and loads, are responsible for controlling the power outputs of distributed units according to both local information and the power commands received from the MGCC.

Frequency control globally consists of primary frequency control and secondary frequency control. The controller of the inverter in the ESs responds in milliseconds during frequency control. Similarly the release of rotor kinetic energy (RKE) of a DFIG can also act in milliseconds. Otherwise, the 
distributed generators (including MT, PV, and wind generator etc.) have a relatively slower response time. According to the differences on response time, the frequency control in islanded operation mode can be divided into two parts, the ESs and RKE act in the primary frequency control, and the others act in the secondary frequency control.

\section{Cooperative Frequency Control}

On the basis of the microgrid control structure, the major innovations of the proposed cooperative frequency control strategy cover both the MGCC and MGLC. In MGCC, the power deficiency prediction and distribution strategy are proposed to achieve the cooperative control of all microgrid units, moreover the HFNNC of DFIG-SMES as well as the SOC control of BES is proposed in MGLC to effectively utilize the corresponding units.

\subsection{Microgrid Central Control}

\subsubsection{Active Power Control}

Figure 3 illustrates the flowchart of the proposed two layered MGCC strategy. The corresponding steps of the two-layer MGCC, including power deficiency prediction and distribution, can be described as follows:

Step 1: Firstly MGCC starts course 1 after the accident simultaneously; meanwhile MGCC monitors and collects the ROCOF and local information from all MGLCs;

Step 2: Ranked second, the power deficiency of the accident is made up by the RKE of DFIGs and ESs during primary frequency control;

Step 3: MGCC predicts the power deficiency $\triangle P$ according to Equation (6), and distributes the power deficiency to DGs and RPC of DFIG as well as loads in secondary frequency control;

Step 4: The active power references calculated by MGCC is distributed to the DGs and controllable loads, then the power deficiency is balanced by the above control strategies, hence the power outputs of the ESs could be restored to secure the maximum emergency reserved power.

Firstly a prediction method to quickly estimate the power deficiency during operation mode transfer or frequency faults is proposed. If ROCOF and equivalent inertial constant $(H)$ are already known, the active power ahh-no get itdeficiency can be derived as:

$$
\Delta P=\frac{2 H}{f_{n}} \frac{d f}{d t}
$$

where $H$ is the equivalent inertial constant of microgrid (s), based on the method proposed in [30], the equivalent inertial constant of the islanded microgrid can be determined. The term $f_{n}$ is the rate frequency $(\mathrm{Hz}), f$ is the real-time frequency of the system; and $\Delta P$ is the active power deficiency in the whole microgrid during the incident. 
Figure 3. Flowchart of a two layered MGCC.

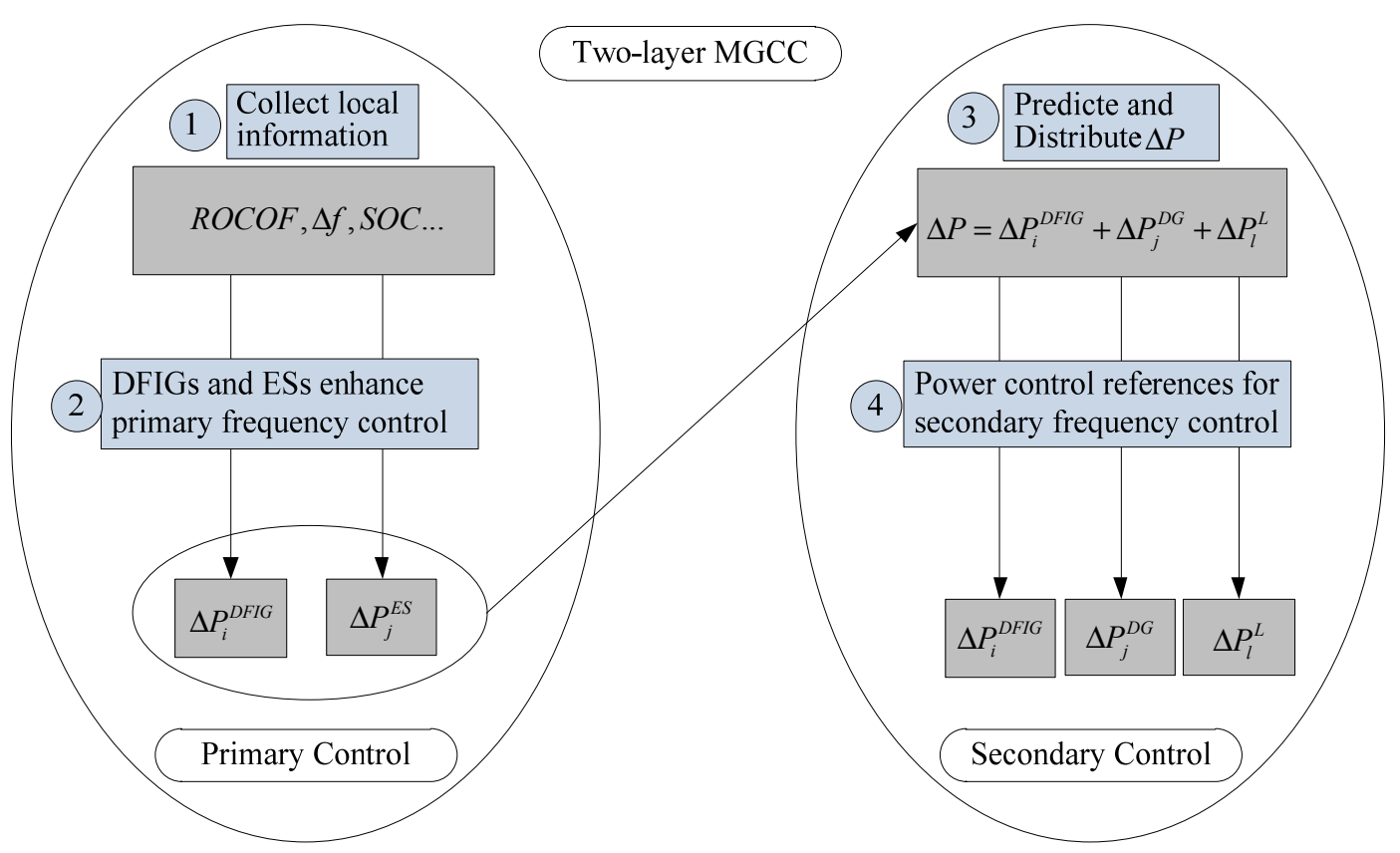

In emergency conditions or islanding operation, MGCC firstly orders the ESs and RKE of DFIG which react quickly to increase the output in order to restore the system in milliseconds. All MGLCs collect and report the operation status to the MGCC in real time. However, the control capabilities of the ESs are limited by their available capacity, meanwhile the SOC control strategy is applied to optimize the ESs lifetimes. Therefore in the primary frequency control, by proper power-balancing action of the ESs and RKE, the frequency of the microgrid can be regulated to the normal values in milliseconds, while in the secondary frequency control, the power output of the ESs should be brought back as soon as possible by the MGCC power distribution to secure the maximum emergency reserve. Depending on the calculated active power deficiency $(\Delta P)$, MGCC coordinates the DGs to increase power outputs to make up the power deficiency instead of ESs and the power output changes of DGs are calculated as follows considering capacity:

$$
\left\{\begin{array}{c}
\Delta P_{i}^{D F I G}=\frac{\xi_{i}^{C} K_{i}^{D F I G} \Delta P}{\sum_{i} \xi_{i}^{C} K_{i}^{D F I G}+\sum_{j} \xi_{j}^{C} K_{j}^{D G}+\sum_{l} \xi_{l}^{C} K_{l}^{L}} \\
\Delta P_{j}^{D G}=\frac{\xi_{j}^{C} K_{j}^{D G} \Delta P}{\sum_{i} \xi_{i}^{C} K_{i}^{D F I G}+\sum_{j} \xi_{j}^{C} K_{j}^{D G}+\sum_{l} \xi_{l}^{C} K_{l}^{L}} \\
\Delta P_{l}^{L}=\frac{\xi_{l}^{C} K_{l}^{L} \Delta P}{\sum_{i} \xi_{i}^{C} K_{i}^{D F I G}+\sum_{j} \xi_{j}^{C} K_{j}^{D G}+\sum_{l} \xi_{l}^{C} K_{l}^{L}}
\end{array}\right.
$$

where $i$ is the $i$ th DFIG unit, $i=1,2, \ldots$; and $j$ is the $j$ th DG unit, $j=1,2, \ldots ; l$ is the $i$ th controllable load unit, $l=1,2, \ldots ; K_{i}^{D F I G}$ is the DFIG participation factor, which is determined based on the ability of the power support in the particular conditions; $K_{j}^{D G}$ is the DG participation factor; $K_{l}^{L}$ is the controllable load participation factor, when $f<49.5 \mathrm{~Hz}, K_{l}^{L}>0 ; \xi_{i}^{C}, \xi_{j}^{C}, \xi_{l}^{C}$ are respectively the capacity upper limit 
determination coefficient of DFIG, DG and controllable load, the capacity judge coefficient is equal to 1 unless it reaches the capacity limit.

\subsubsection{Reactive Power Control}

As illustrated in the previous section, the corresponding reactive power control under the two-layer frequency control structure is shown in Figure 4. Firstly during the primary frequency control, MGCC starts the reactive power control of ESs immediately after the incident by PQ to VF control; than in the secondary frequency control, MGCC distributes the reactive power deficiency to DGs as the active power control. Based on the above power distribution strategy, the reactive power references can be calculated and distributed to the available DGs by the MGCC, hence the power output of the ESs could be brought back to secure the maximum emergency spinning power.

Figure 4. Two layered reactive power control.

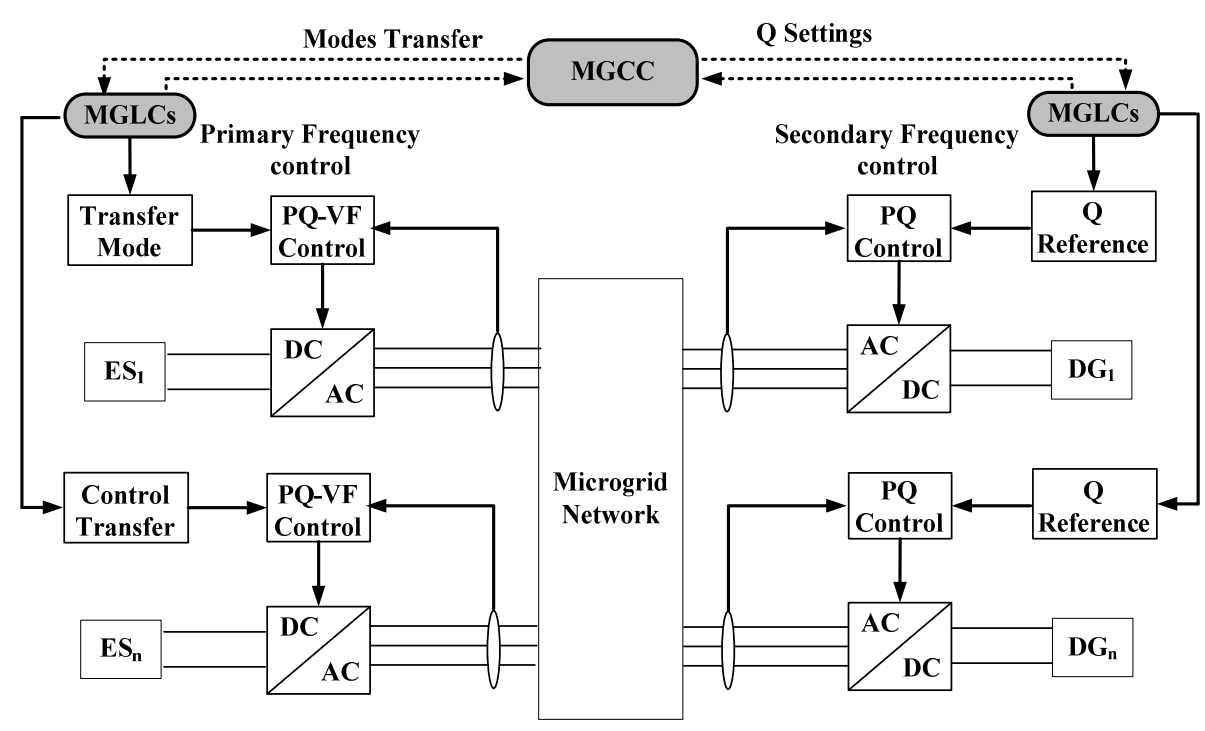

\subsection{Microgrid Local Control}

\subsubsection{DFIG-SMES Local Control}

For the DFIG-SMES module, the proposed cooperative control strategy involves rotor kinetic energy control (RKEC) and reserved power control (RPC) of DFIG and energy control of SMES. Meanwhile Hopfield fuzzy neural network control (HFNNC) method is utilized to get more reasonable control reference values for the corresponding local controls [31,32]. Compared with the traditional PID control approach, the proposed HFNNC can not only execute the function of controller without an accurate mathematical model, but also can improve the robustness of the controller according to the operation characteristics of the microgrid.

The core of the cooperative control design is the Hopfield fuzzy neural network control scheme. The HFNNC A gets more reasonable torque $T_{\text {ref }}$ reference by optimization of the Hopfield method. Through HFNNC A, the DFIG releases the rotor kinetic energy in milliseconds to support the primary frequency modulation. Secondly, the HFNNC B increases the power output by adjustment of pitch 
angle to provide the frequency support. Finally, the HFNNC C controls the active power output of SMES, and SMES releases stored power to improve frequency control ability of DFIG-SMES, as shown in Figure 5.

Figure 5. Frequency control of DFIG-SMES.

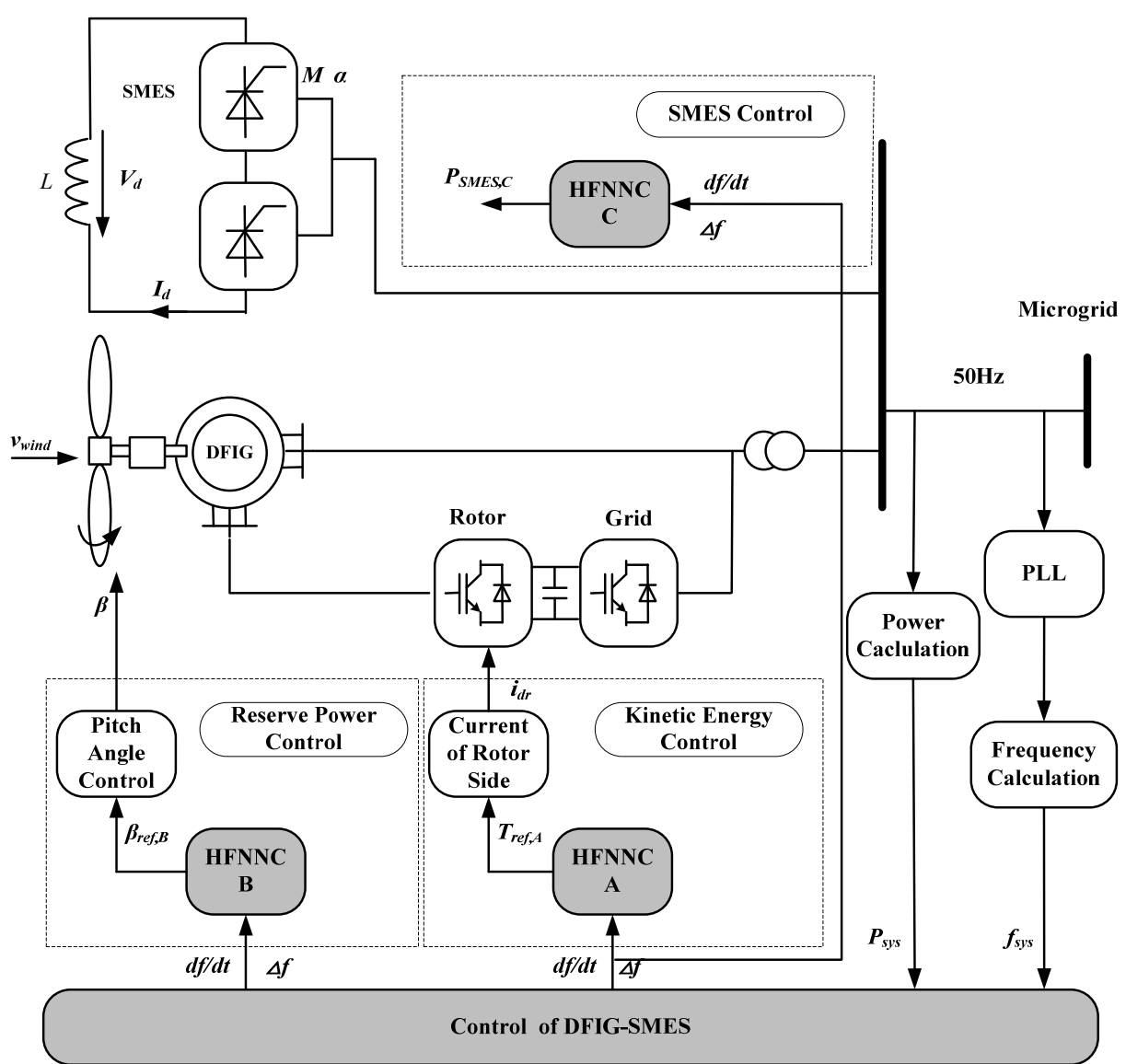

The control object of HFNNC A, B and C can be identified as follows:

$$
\left\{\begin{array}{l}
\Delta T_{r e f}=-K_{f 1} \Delta f-K_{d f 1} \frac{d f}{d t} \\
\Delta \beta_{r e f}=-K_{f 2} \Delta f-K_{d f 2} \frac{d f}{d t} \\
\Delta P_{r e f}=-K_{f 3} \Delta f-K_{d f 3} \frac{d f}{d t}
\end{array}\right.
$$

where $\Delta T_{\text {ref }} \Delta \beta_{\text {ref }} \Delta P_{\text {ref }}$ are respectively the output of HFNNC A B and C; $\Delta f$ and $d f l d t$ are inputs of controllers; $K_{f 1} K_{f 2} K_{f 3}$ are corresponding proportion coefficients, while $K_{d f 1} K_{d f 2} K_{d f 3}$ are differential coefficients. Assume that the system can expressed as $y(t)=C[A x(t)+B u(t)]$. Then the output of PD controller can be derived as follows: 


$$
u(t)=k_{p} e(t)+k_{d} \frac{d e(t)}{d t}
$$

where $e(t)$ is the system frequency error; $r(t)$ is the rated frequency which is a constant value; and $y(t)$ is the current frequency value, so the objective function of control system can be described as:

$$
\begin{aligned}
& E(t)=\frac{1}{2} e^{2}(t)=\frac{1}{2}[r(t)-y(t)]^{2}=\frac{1}{2}\{r(t)-C[A x(t)+B u(t)]\}^{2} \\
& =\frac{1}{2}\left\{r(t)-C\left[A x(t)+B\left(k_{p}(t) e(t)+k_{d}(t) \frac{d e(t)}{d t}\right)\right]\right\}^{2}
\end{aligned}
$$

With the parameters $\mathrm{P}$ and $\mathrm{D}$ of the controller proposed in this paper, a Hopfield neural network with two neurons is designed for the optimization of HFNNC. The output of HFNNC can be derived as:

$$
\mathbf{V}(t)=\left[V_{1}(t), V_{2}(t)\right]^{T}=\left[k_{p}(t), k_{d}(t)\right]^{T}
$$

Assume that the input resistance is infinite, then we substitute $V_{1}=k_{p}, V_{2}=k_{d}$, so the standard energy function can be expressed as:

$$
\begin{aligned}
E_{N}(t)= & -1 / 2\left[w_{11}(t) k_{p}(t) k_{p}(t)+w_{12}(t) k_{p}(t) k_{d}(t)\right. \\
& \left.+w_{21}(t) k_{d}(t) k_{p}(t)+w_{22}(t) k_{d}(t) k_{d}(t)\right] \\
& -k_{p}(t) I_{1}(t)-k_{d}(t) I_{2}(t)
\end{aligned}
$$

By matching the target function to the energy function of Hopfield networks, the matrix $W$ and $I$ are constructed in the following format:

$$
\begin{aligned}
& W=-\left[\begin{array}{cc}
{[C B e(t)]^{2}} & 2 B^{2} C^{2} e(t) \frac{d e(t)}{d t} \\
2 B^{2} C^{2} e(t) \frac{d e(t)}{d t} & {\left[C B \frac{d e(t)}{d t}\right]^{2}}
\end{array}\right] \\
& I=\left[\begin{array}{c}
-2 A B C^{2} e(t) x(t)+2 B C r(t) e(t) \\
-2 A B C^{2} \frac{d e(t)}{d t} x(t)+2 B C r(t) \frac{d e(t)}{d t}
\end{array}\right]^{T}
\end{aligned}
$$

Take the symmetric nonlinear S function as the nonlinear output characteristics of the neurons, the change rule of parameter $k_{p}, k_{d}$ can be represented by: 


$$
\begin{aligned}
& \frac{d k_{p}}{d t}= \frac{d k_{p}}{d u_{1}} \frac{d u_{1}}{d t}=\frac{\beta_{1}\left(K_{1}^{2}-k_{p}^{2}\right)}{2 K_{1}}\left(-B^{2} C^{2} e^{2} g\left(u_{1}\right)\right. \\
&\left.+2 B^{2} C^{2} e \frac{d e}{d t} g\left(u_{2}\right)-2 A B C^{2} e x+2 B C r e\right) \\
& \frac{d k_{d}}{d t}= \frac{d k_{d}}{d u_{2}} \frac{d u_{2}}{d t}=\frac{\beta_{2}\left(K_{2}^{2}-k_{d}^{2}\right)}{2 K_{2}}\left(2 B^{2} C^{2} e \frac{d e}{d t} g\left(u_{1}\right)\right. \\
&\left.-B^{2} C^{2}\left(\frac{d e}{d t}\right)^{2} g\left(u_{2}\right)-2 A B C^{2} \frac{d e}{d t} x+2 B C r \frac{d e}{d t}\right)
\end{aligned}
$$

The two parameters $k_{p}, k_{d}$ which are under a particular optimal control law can be found by solving differential Equations $(15,16)$.

\subsubsection{BES Local Control}

The SOC control in order to extend the service life of BES is presented in this section. Real time information of each BES is monitored and fed back to the battery control, hence the control command of discharge/charge would be sent according to the SOC control rules shown in Table 1.

Table 1. Rules of SOC participation factor.

\begin{tabular}{cccc}
\hline$\Delta \boldsymbol{f}$ & $\boldsymbol{S O C} \leq \boldsymbol{S O C}_{\min }$ & $\boldsymbol{S O C}_{\min }<\boldsymbol{S O C} \leq \boldsymbol{S O C}_{\max }$ & $\boldsymbol{S O C} \boldsymbol{S O C}_{\max }$ \\
\hline$\Delta f<\Delta f_{\min }$ & 0 & 1 & 1 \\
$\Delta f_{\min } \leq \Delta f_{s y s}<0$ & 0 & 0 & 1 \\
$\Delta f=0$ & 0 & 0 & 0 \\
$0<\Delta f \leq \Delta f_{\max }$ & 0 & 0 & 1 \\
$\Delta f>\Delta f_{\max }$ & 0 & 1 & 1 \\
\hline
\end{tabular}

According to Table 1, the main operation rules of the battery can be described as follows:

$>$ Discharge the battery when $\Delta f<\Delta f_{\min }$ and $S O C>S O C_{\min }$;

$>$ Discharge the battery when $S O C>S O C_{\max }$ and $\triangle f>0$;

$>\varsigma^{S O C}$ becomes to 0 when $S O C \leq S O C_{\min }$;

Idle the battery when $|\Delta f|<15 \mathrm{mHz}$ and $S O C_{\min }<S O C \leq S O C_{\max }$.

The participation factor coefficient of SOC is the key issue for the BES charging and discharging management. The control structure of the BES local control scheme considering the SOC participation factor is presented in Figure 6.

At first, the SOC of each BES is defined and calculated by the Equation (6) in real time in Section 2, and accordingly the SOC control strategy described in Table 1 is utilized to make the necessary decisions for BES control. Based on the participation factors and the current SOC value, the charging or discharging capacity can be determined. 
Figure 6. SOC local control structure.

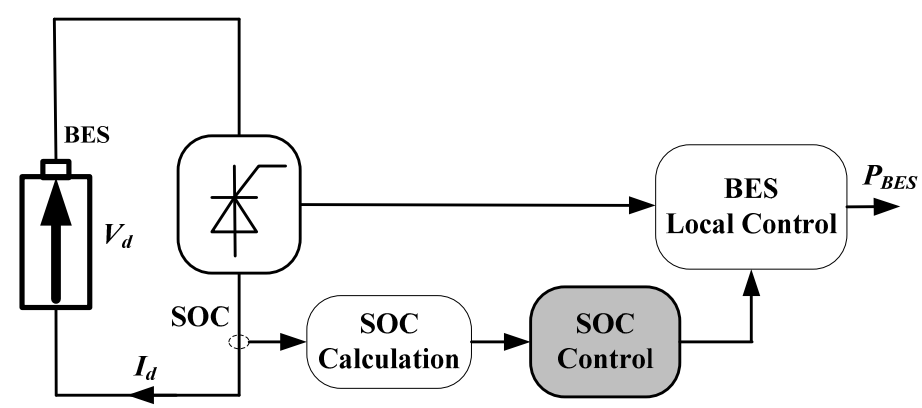

\section{Simulation Results}

The simulation microgrid is a grid-connected comprehensive planning demonstration project located on an offshore island in China. The programming microgrid can operate in the grid-connected and islanded modes and realize flexible transfer between these two modes after completion. The wind power penetration of the microgrid is high due to the rich available wind energy resource along the shoreline. Therefore, more attention is paid to the frequency control ability of the DFIG, hence the auxiliary control is utilized to release rotor kinetic energy of DFIG to support the system frequency stability. Meanwhile, the DFIG operates in power reserve mode and increases the power output and makes up the power shortage during sizeable frequency deviations.

The configuration of the simulated microgrid used in this paper is shown in Figure 7. It is composed of a $0.38 \mathrm{kV}$ distributed subsystem connected to a $10 \mathrm{kV}$ distribution network through a $100 \mathrm{kVA}$ transformer. The microgrid includes $400 \mathrm{~kW}$ of MT, $275 \mathrm{~kW}$ of DFIG, $60 \mathrm{~kW}$ of PV, $20 \mathrm{~kW}$ of SMES, $20 \mathrm{~kW} \mathrm{BES}{ }_{1}, 25 \mathrm{~kW}$ of $\mathrm{BES}_{2}$ and loads (including controllable loads and uninterruptible loads).

Figure 7. Simulation microgrid.

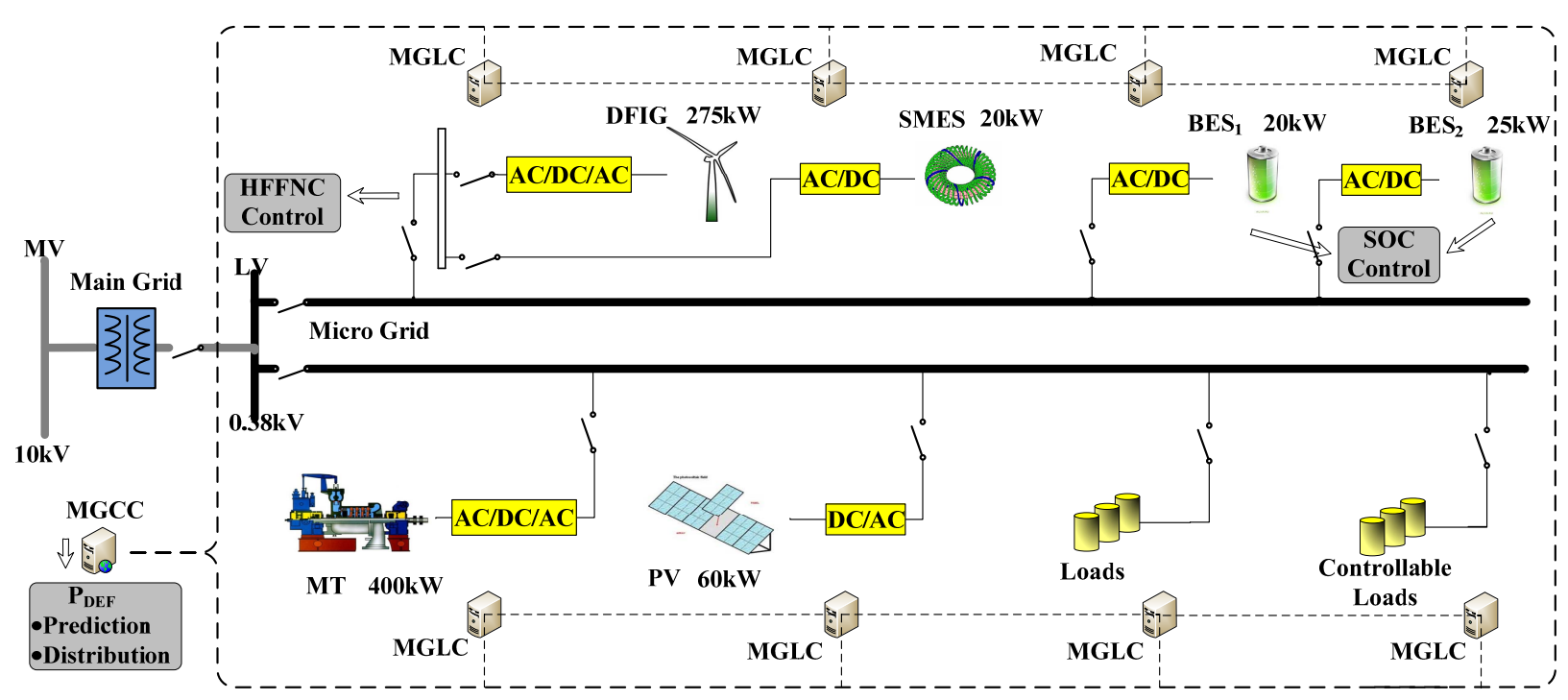

In order to demonstrate the efficiency of the proposed approach for frequency stabilization, the above microgrid with DFIG-SMES module was developed based on the PSCAD/EMTDC platform. The proposed control strategies including MGCC and MGLC (HFNNC and SOC) are compiled in 
MATLAB, taking advantages of the mathematical treatment possibilities of this software. Then the PSCAD model and MATLAB programs are connected together through a Fortran language-based interface procedure. The proposed control strategies are illustrated and studied in this paper with this coordinated PSCAD and MATLAB simulation technology.

\subsection{Case A: Operation Mode Transfer}

At the beginning of the simulation case, the microgrid works in a well-balanced state. MT operates in VF mode. PV operates in maximum power point tracking (MPPT) mode. DFIG operates in power reserved mode and with RKE in the wind turbine blades. SMES and BES works in PQ mode. The proposed SOC and HFNNC control strategies are applied to restore the frequency of microgrid during frequency incidents.

In the steady state of case A, the output power of MT is $180 \mathrm{~kW}$, the PV is $60 \mathrm{~kW}$, the DFIG is $105 \mathrm{~kW}$, and the speed of wind in the simulated area maintains at $12 \mathrm{~m} / \mathrm{s}$, the controllable loads are $185 \mathrm{~kW}$, constant loads are $220 \mathrm{~kW}$.

When $t=2 \mathrm{~s}$, the microgrid separates from main grid because of the three-phase short-circuit fault of the main grid, the operation mode transfers from grid-connected mode to islanded mode, consequently the transmission power of the tie-line is lost. The control curves are shown in Figure 8.

SOC Control: Assume that $\Delta f_{\min }=-25 \mathrm{mHz}, \Delta f_{\max }=25 \mathrm{mHz}$; and $S O C_{\min }=10 \%, S O C_{\max }=90 \%$, hence the performances of sthe imulated BESs are described in Figure 8a. The initial SOC of BESs are $\mathrm{BES}_{1}=75 \%, \mathrm{BES}_{2}=48 \%$, respectively. As seen in Figure 8a, the power output increase of $\mathrm{BES}_{1}$ is larger than that of $\mathrm{BES}_{2}$ according to the rules of the Table 1, the available power of $\mathrm{BES}_{1}$ is $C_{\text {total } 1}(75 \%-10 \%)$, while that of $\mathrm{BES}_{2}$ is $C_{\text {total }}(48 \%-10 \%)$.

HFNNC: In this case, HFNNC A, B and C are applied to give support to the frequency control. The local HFNNC A and C are triggered at the primary frequency control, while the HFNNC B is launched after power distribution at the secondary frequency control, as shown in Figure $8 \mathrm{~b}$. The effect of HFNNC for frequency stability can be seen in Figure 8d.

MGCC: As MGCC picks the ROCOF and computes the equivalent inertia $H$ of the microgrid in real time, in such an emergency condition, MGCC uses the real-time ROCOF and $H$ value to estimate the magnitude of the active power deficiency.

Firstly, based on the method we proposed in [30], the equivalent inertia $H$ of the simulation microgrid can be calculated in real time, which is 0.00996 in this case. Then, according to the ROCOF monitored by MGCC, the value of which is -1.5 . Based on Equation (6), the magnitude of the active power deficiency can be determined, $\Delta P=-5.976 \times 10^{-4}$. The calculated $\Delta P$ above is the per-unit value, and the base power is $P_{B}=100 \mathrm{MW}$, so the active power deficiency of the whole microgrid is $59.76 \mathrm{~kW}$. The MGCC gets to know that it is necessary to increase the output of each distributed generator or energy device to make up the power deficiency at this moment, so MGCC distributes the power commands to the MGLCs which have available power based on the collected local information. 
Figure 8. Control performance with the proposed control in case A. (a) Active power outputs of BESs by SOC control; (b) Active power outputs of DFIG-SMES by HFNNC contro; (c) Active power outputs of DGs; (d) Frequency responses of different control methods; (e) Reactive power outputs of DERs; (f) Voltage responses of different control methods.



(a)

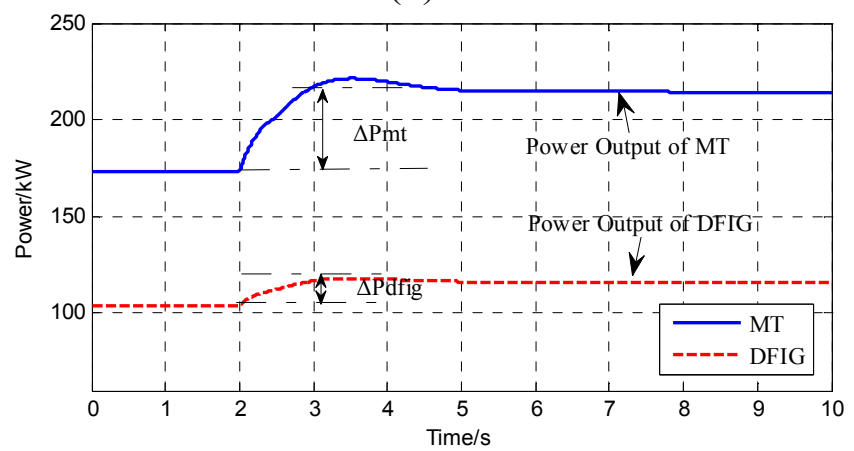

(c)

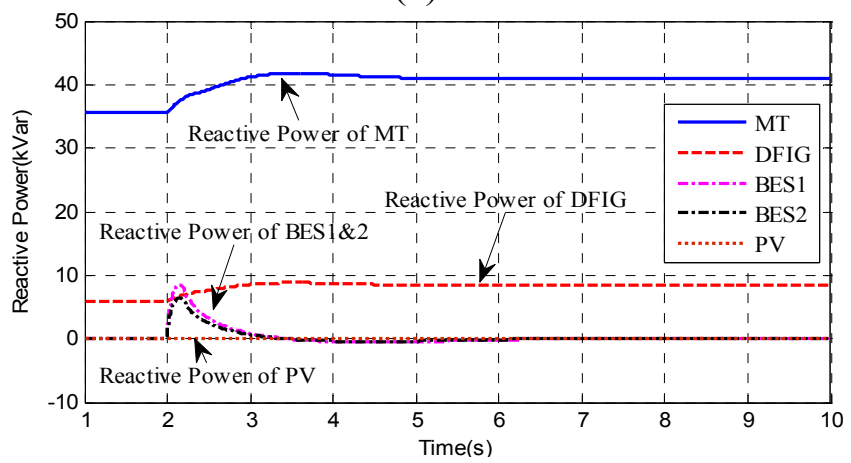

(e)

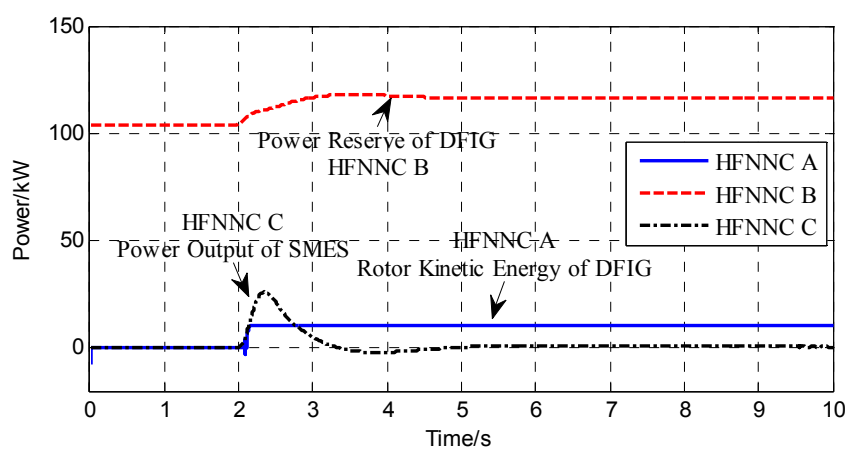

(b)

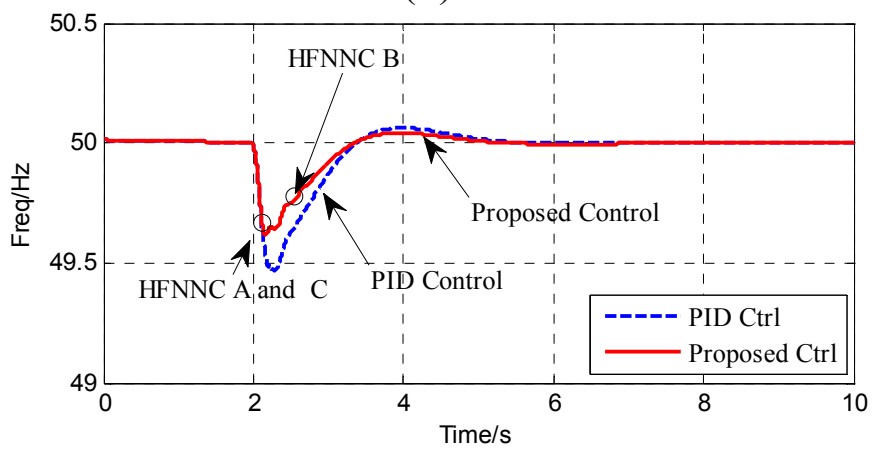

(d)

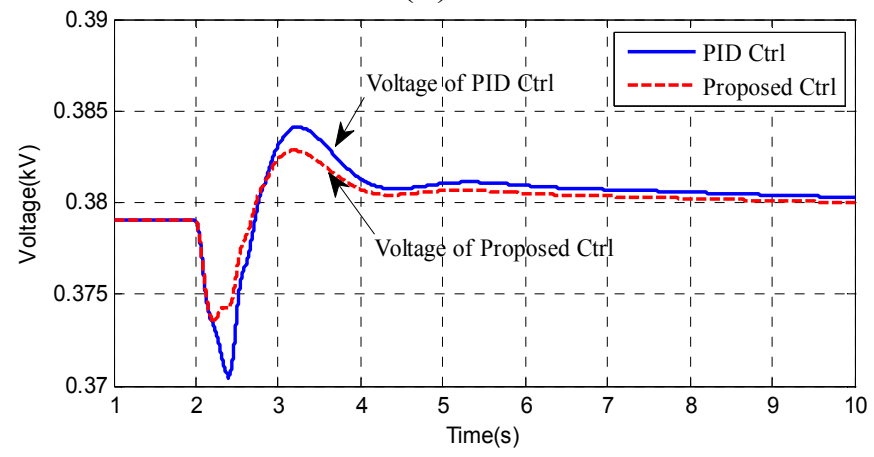

(f)

According to the operation information of the simulation system, we set $i=1, j=2, l=1$; and $K_{l}^{L}=0$ because the system frequency $f>49.5 \mathrm{~Hz}, K_{i}^{D F I G}=20 \%, K_{j}^{D G}=80 \% ; \xi_{i}^{C}, \xi_{j}^{C}, \xi_{l}^{C}$ are respectively dependent on the capacity upper limit of each distributed generator and storage unit.

We observe from the solid curve of Figure 8c, that the output change of the DG is $48 \mathrm{~kW}$, and the power output increase of the DFIG is $12 \mathrm{~kW}$ (dashed line), which is approximately equal to the power commands calculated from the following equations, so the MGCC power deficiency prediction and distribution method can reasonably distribute the power and loads of a microgrid for cooperative frequency support: 


$$
\left\{\begin{array}{l}
\Delta P_{1}^{D F I G}=\frac{\xi_{i}^{C} K_{i}^{D F I G} \Delta P}{\sum_{1} \xi_{i}^{C} K_{i}^{D F I G}+\sum_{2} \xi_{j}^{C} K_{j}^{D G}}=11.95 \mathrm{~kW} \\
\Delta P_{1}^{D G}=\frac{\xi_{1}^{C} K_{1}^{D G} \Delta P}{\sum_{1} \xi_{i}^{C} K_{i}^{D F I G}+\sum_{2} \xi_{j}^{C} K_{j}^{D G}}=47.81 \mathrm{~kW}
\end{array}\right.
$$

Observed from Figure 8d, it is necessary to execute load shedding because the frequency in the solid line is lower than $49.5 \mathrm{~Hz}$. While in the dashed line, the power deficiency is offset by the cooperative control of the microgrid including both MGCC and the HFNNC of DFIG-SMES, the corresponding frequency of the islanded microgrid in this case becomes higher than $49.5 \mathrm{~Hz}$ by the proposed cooperative control, which avoids the measure of load shedding and decreases the cost of operation compared with the commonly used PID control strategy.

For the proposed cooperative frequency control method, the reactive power outputs of the DERs can be seen in the Figure 8e. At $t=4 \mathrm{~s}$, the outputs of both $\mathrm{BES}_{1}$ and $\mathrm{BES}_{2}$ are brought back to zero by the distribution of MGCC as shown in Figure 4. The corresponding voltage response of the proposed control method, which can be observed from the dashed line in Figure 8f, is stable during the islanding operation. Compared with the voltage curve of the PID control, which lowest voltage is higher, the voltage can recover faster because of the quick prediction and reasonable control made by the proposed cooperative control method.

\subsection{Case B: Fault in Islanded Mode}

In case $\mathrm{B}$, the simulation microgrid works in islanded operation mode, and the autonomous microgrid operates in well-balanced state. Similar to the case A, MT works in VF mode. PV operates in maximum power point tracking (MPPT) mode. DFIG operates in power reserved mode and with rotor kinetic energy in the wind turbine blades. Both SMES and BES operate in PQ mode. The proposed SOC and HFNNC control strategies are applied to restore frequency of the microgrid system during frequency incidents.

In the steady state of case B, the output power of MT is $400 \mathrm{~kW}$, the PV is $60 \mathrm{~kW}$, the DFIG is $105 \mathrm{~kW}$, and the speed of wind in the simulated area is $12 \mathrm{~m} / \mathrm{s}$, the controllable loads are $225 \mathrm{~kW}$, constant loads are $340 \mathrm{~kW}$. When $t=2 \mathrm{~s}$, the autonomous microgrid undergoes a power disturbance incident, and as a result the power balance between supply and demand does not match at the moment and the frequency starts to fluctuate. The performance of the frequency control is this case is as follows:

SOC Control: For case B, assume that $\Delta f_{\min }=-30 \mathrm{mHZ}, \Delta f_{\max }=30 \mathrm{mHz}$ because the frequency fluctuation of the islanded microgrid is larger than that of a grid-connected microgrid. In addition, the $S O C_{\min }=10 \%, S O C_{\max }=90 \%$ as case A, and the performances of simulated BESs are described in Figure 9a. As seen in Figure 8a, the power output increase of $\mathrm{BES}_{1}$ is smaller than that of $\mathrm{BES}_{2}$ opposite to case A, because that the available power of $\mathrm{BES}_{2}$ is $C_{\text {total } 2}(98 \%-10 \%)$, larger than that of $\mathrm{BES}_{1}$, which is still $C_{\text {total } 1}(75 \%-10 \%)$. 
Figure 9. Control performance with the proposed control scheme in case B. (a) Active power outputs of BESs by SOC control; (b) Active power outputs of DFIG-SMES by HFNNC control; (c) Active power outputs of DGs; (d) Frequency responses of different control methods; (e) Reactive power outputs of DERs; (f) Voltage responses of different control methods.

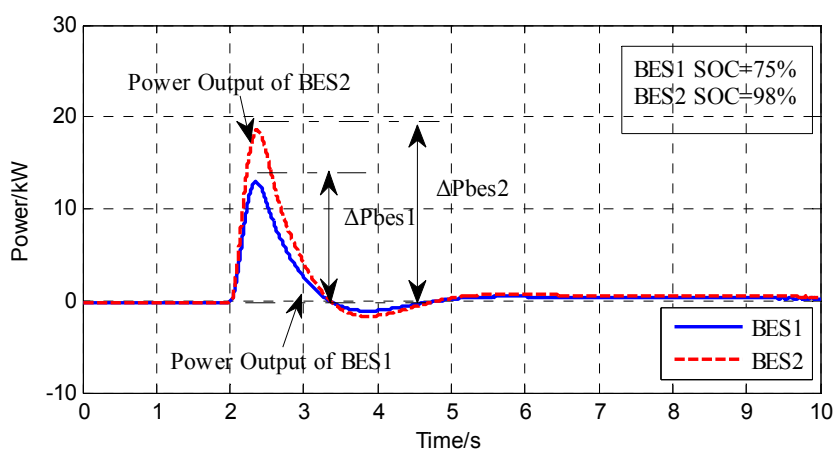

(a)

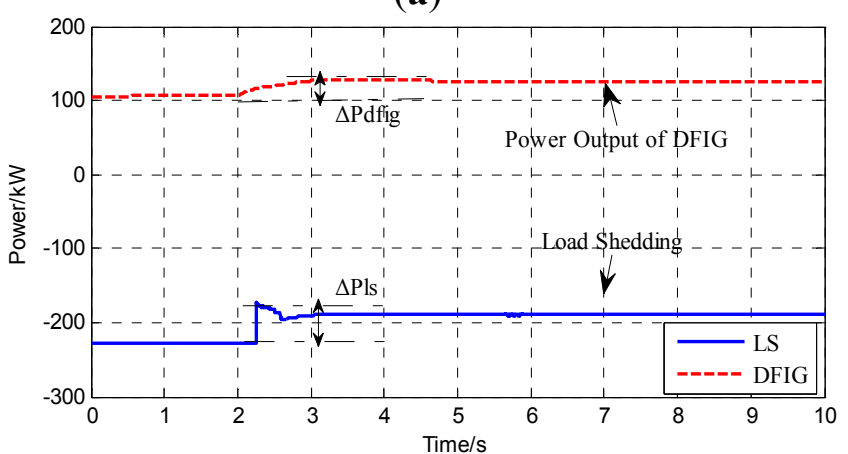

(c)

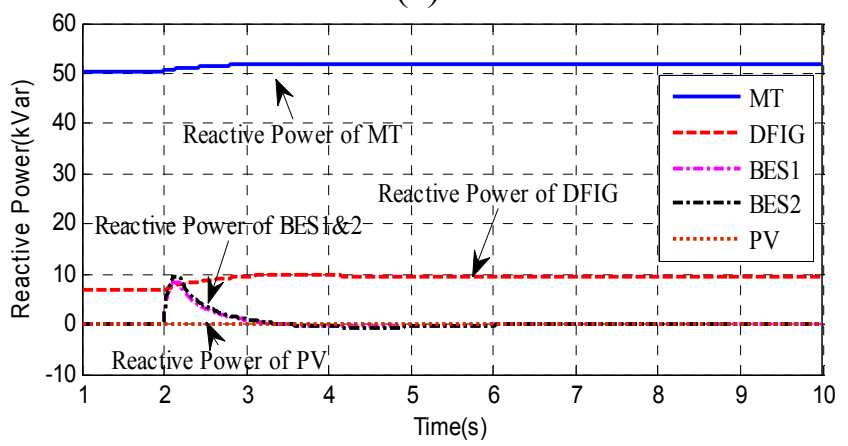

(e)

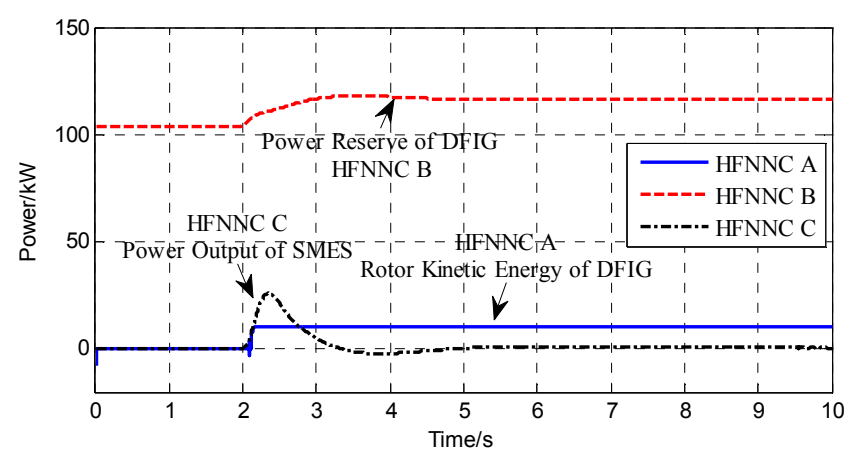

(b)

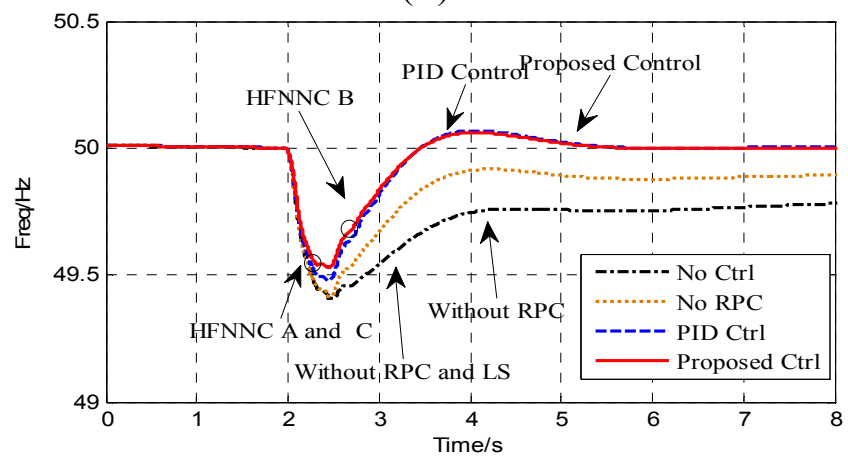

(d)

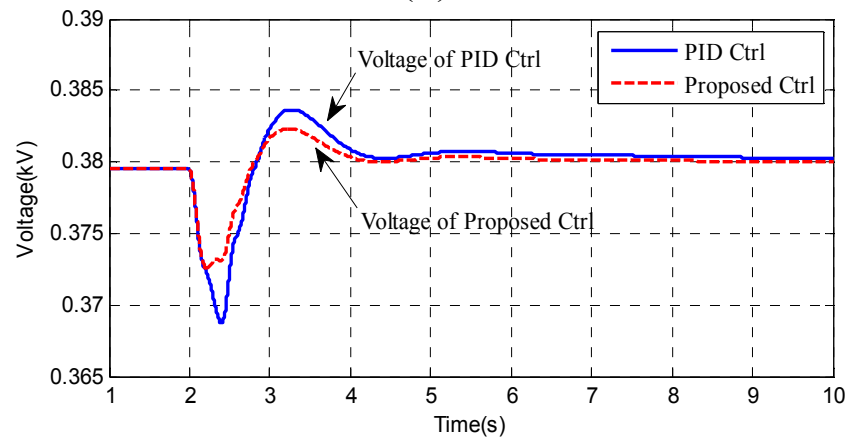

(f)

HFNNC: In this case, the HFNNC A and C are put into effect immediately after the prediction of a power deficiency, the HFNNC $\mathrm{C}$ and load shedding are triggered after the power distribution of MGCC, as is shown in Figure $9 \mathrm{~b}$. The effect of HFNNC for frequency stability can be seen from Figure 10d.

MGCC: In case $\mathrm{B}$ the ROCOF is -1.97 and the $H$ value is 0.00996 . Based on Equation (6), the magnitude of active power deficiency at this moment can be achieved as $\Delta P=-7.849 \times 10^{-4}$. According to the result above, the active power deficiency of the whole microgrid is $78.49 \mathrm{~kW}$. After analyzing the information collected from MGLCs, MGCC gets to know that it is impossible for MT to increase the output because of its capacity limit, so the power distribution of other distributed generations and loads are as follows: 
According to the operation information of the simulation system in this case, we set $i=1, j=2, l=1$; and $K_{l}^{L}=0$ because the system frequency $f>49.5 \mathrm{~Hz}, K_{i}^{D F I G}=40 \%, K_{l}^{L}=60 \% ; \xi_{i}{ }^{C}, \xi_{j}{ }^{C}, \xi_{l}^{C}$ are dependent on the available power of each distributed generator and storage, respectively, so the power can be distributed as follows:

$$
\left\{\begin{array}{l}
\Delta P_{1}^{D F I G}=\frac{\xi_{i}^{C} K_{i}^{D F I G} \Delta P}{\sum_{1} \xi_{i}^{C} K_{i}^{D F I G}+\sum_{2} \xi_{l}^{C} K_{l}^{L}}=31.39 \mathrm{~kW} \\
\Delta P_{1}^{L}=\frac{\xi_{1}^{C} K_{1}^{L} \Delta P}{\sum_{1} \xi_{i}^{C} K_{i}^{D F I G}+\sum_{2} \xi_{l}^{C} K_{l}^{L}}=47.10 \mathrm{~kW}
\end{array}\right.
$$

We observe from the dashed line of Figure 9c, that the power increase of the DFIG is $32 \mathrm{~kW}$, while the load shedding of the controllable load is $48 \mathrm{~kW}$ in the solid line, which is approximately consistent with the power references calculated from MGCC, so with the power deficiency prediction and distribution of MGCC, the power and loads of the microgrid are reasonably distributed and effectively utilized.

In addition to displaying the superiority of HFNNC over PID control in Figure 8d, Figure 9d also aims at showing the frequency support contribution of DFIG in an islanded microgrid. It is obvious that the frequency of the islanded microgrid cannot recover to $50 \mathrm{~Hz}$ because the MT provides no contribution to frequency control because of its capacity limit and lack of HFNNC and load shedding (LS) control. Even deloading the same load as the proposed control strategy, the frequency of the microgrid could not recover to $50 \mathrm{~Hz}$ without the RPC of DFIG, as can be seen from the dotted curve in the figure, while in the dashed curve, the frequency can restore to $50 \mathrm{~Hz}$ through traditional PID control with the RPC of DFIG, and moreover the proposed cooperative frequency control in the solid curve is more effective than the PID control.

The reactive power outputs of the DERs and the voltage response of the simulation microgrid under the proposed frequency control strategy are shown in Figure 9e,f, respectively. As observed from Figure 9e, the reactive power outputs of BESs are brought back to zero to ensure sufficient power reserves, while in Figure $9 f$, the voltage response of the microgrid in the dashed line recovers faster than that of the solid line, and the voltage can maintain stable during the frequency control process in islanded operation mode.

The simulation results above, which are based on a device-level electromagnetic transient simulation platform, can fully illustrate the feasibility and validity of the proposed method. In order to apply the proposed method in a practical microgrid, experimental tests in a microgrid laboratory considering communication constraints and system topology changes are needed.

\section{Conclusions}

A two-layer cooperative frequency control scheme for microgrids has been presented and simulated in this paper. The simulation results have demonstrated that the proposed cooperative frequency control strategy can effectively enhance the frequency stability of a microgrid both during islanding and under islanded operation mode. The centralized MGCC can accurately estimate the power deficiency and accordingly distribute the power commands to achieve cooperative control of all 
microgrid units. Meanwhile the local HFNNC can effectively improve the robustness of thebcontroller and make frequency control approaches more adaptive then traditional PI control. In addition, the presented SOC control scheme can contribute to extend the battery life of BES.

\section{Acknowledgments}

This work was supported in part by the National High Technology Research and Development Program of China (863 Program Grant No. 2011AA05A107), the National Science Foundation of China (Grant No. 50907008 and 51277027) and the Fundamental Research Funds for the Central Universities.

\section{References}

1. Moslehi, K.; Kumar, R. A reliability perspective of smart grid. IEEE Trans. Smart Grid 2010, $1,57-64$.

2. Heydt, G.T. The next generation of power distribution systems. IEEE Trans. Smart Grid 2010, 1, 225-235.

3. Li, J.; Wei, W.; Xiang, J. A simple sizing algorithm for stand-alone PV/Wind/Battery hybrid microgrids. Energies 2012, 5, 5307-5323.

4. Yao, Z.; Xiao, L.; Yan, Y. Seamless transfer of single-phase grid interactive inverters between grid connected and stand-alone modes. IEEE Trans. Power Electron. 2010, 25, 1597-1603.

5. Pogaku, N.; Prodanovic, M.; Green, T.C. Modeling, analysis and testing of autonomous operation of an inverter-based microgrid. IEEE Trans. Power Electron. 2007, 22, 613-625.

6. Kim, H.M.; Kinoshita, T.; Shin, M.C. A multiagent system for autonomous operation of islanded microgrids based on a power market environment. Energies 2010, 3, 1972-1990.

7. Diaz, G.; Gonzalez-Moran, C.; Gomez-Aleixandre, J.; Diez, A. Complex-valued state matrices for simple representation of large autonomous microgrids supplied by $\mathrm{P}_{\mathrm{Q}}$ and $\mathrm{V}_{\mathrm{f}}$ generation. IEEE Trans. Power Syst. 2009, 24, 1720-1730.

8. Vandoorn, T.L.; Renders, B.; Degroote, L. Active load control in islanded microgrids based on the grid voltage. IEEE Trans. Smart Grid 2011, 2, 139-151.

9. Oudalov, A.; Chartouni, D.; Ohler, C. Optimizing a battery energy storage system for primary frequency control. IEEE Trans. Power Sys. 2007, 22, 1259-1266.

10. Steurer, M.; Hribernik, W. Frequency response characteristics of a 100 MJ SMES coil measurements and model refinement. IEEE Trans. Appl. Supercond. 2005, 15, 1887-1890.

11. Tsutsui, H.; Nomura, S.; Shimada, R. Optimization of SMES coil by using virial theorem. IEEE Trans. Appl. Supercond. 2002, 12, 800-803.

12. Papadimitriou, C.N.; Vovos, N.A. Transient response improvement of microgrids exploiting the inertia of a Doubly-Fed Induction Generator (DFIG). Energies 2010, 3, 1049-1066.

13. Morren, J.; de Haan, S.W.H.; Kling, W.L.; Ferreira, J.A. Wind turbines emulating inertia and supporting primary frequency control. IEEE Trans. Power Sys. 2006, 21, 433-434.

14. Nomura, S.; Ohata, Y.; Hagita, T. Wind farms linked by SMES systems. IEEE Trans. Power Electron. 2005, 15, 1951-1954. 
15. Keung, P.K.; Li, P.; Banakar, H.; Ooi, B.T. Kinetic energy of wind turbine generators for system frequency support. IEEE Trans. Power Sys. 2009, 24, 279-287.

16. Sheikh, M.R.I.; Muyeen, S.M.; Takahashi, R.; Tamura, J. Alleviation of power fluctuation in interconnected power systems with wind farm by SMES with optimal coil size. IEEE Trans. Appl. Supercond. 2012, 22, doi: 10.1109/TASC.2011.2178984.

17. Zhou, F.; Joos, G.; Abbey, C.; Jiao, L.; Ooi, B.T. Use of large capacity smes to improve the power quality and stability of wind farms. IEEE PES Gen. Meet. 2004, 2, 2025-2030.

18. Tsikalakis, A.; Hatzargyriou, N. Centralized control for optimizing microgrids operation. IEEE Trans. Energy Convers. 2008, 23, 241-248.

19. Katiraei, F.; Iravani, M.R. Power management strategies for a microgrid with multiple distributed generation units. IEEE Trans. Power Sys. 2008, 21, 1821-1831.

20. Mohamed, Y.A.I.; Radwan, A.A. Hierarchical control system for robust microgrid operation and seamless mode transfer in active distribution systems. IEEE Trans. Smart Grid 2011, 2, 352-362.

21. Kim, J.Y.; Jeon, J.H.; Kim, S.K.; Cho, C.; Park, J.H.; Kim, H.M.; Nam, K.Y. Cooperative control strategy of energy storage system and microsources for stabilizing the microgrid during islanded operation. IEEE Trans. Power Electron. 2010, 25, 3037-3048.

22. Kundur, P. Control of Active Power and Reactive Power. In Power System Stability and Control, 1st ed.; McGraw-Hill: New York, NY, USA, 1994.

23. Lopes, J.A.P.; Moreira, C.L.; Madureira, A.G. Defining control strategies for microgrids islanded operation. IEEE Trans. Power Syst. 2006, 21, 916-924.

24. Molina, M.G.; Mercado, P.E. Power flow stabilization and control of microgrid with wind generation by superconducting magnetic energy storage. IEEE Trans. Power Electron. 2011, 26, 910-922.

25. Wang, Z.; Zheng, Y.; Cheng, M.; Fan, S. Unified control for a wind turbine-superconducting magnetic energy storage hybrid system based on current source converters. IEEE Trans. Magn. 2012, 48, 3973-3976.

26. Iglesias, I.J.; Bautista, A.; Visiers, M. Experimental and simulated result of a smes fed by a current source inverter. IEEE Trans. Appl. Supercond. 1997, 7, 861-864.

27. Rabbani, M.G.; Devotta, J.B.X.; Elangovan, S. Application of simultaneous active and reactive power modulation of smes unit under unequal mode for power system stabilization. IEEE Trans. Power Syst. 1999, 14, 547-552.

28. Divya, K.C.; Stergaard, J. Battery energy storage technology for power systems-An overview. Electr. Power Syst. Res. 2009, 79, 511-520.

29. Jongerden, M.R.; Haverkort, B.R. Which battery model to use. IET Softw. 2009, 3, 445-457.

30. Gu, W.; Liu, W.; Shen, C.; Wu, Z. Multi-stage underfrequency load shedding for islanded microgrid with equivalent inertia constant analysis. Int. J. Electr. Power Energy Syst. 2013, 46, $36-39$.

31. Mokadem, M.E.; Courtecuisse, V.; Saudemont, C.; Robyns, B.; Deuse, J. Fuzzy logic supervisor-based primary frequency control experiments of a variable-speed wind generator. IEEE Trans. Power Syst. 2009, 24, 407-417. 
32. Zhang, C.Q.; Fadali, M.S. Nonlinear system identification using a Gabor/Hopfield network. IEEE Trans. Power Syst. 1996, 26, 124-134.

(C) 2013 by the authors; licensee MDPI, Basel, Switzerland. This article is an open access article distributed under the terms and conditions of the Creative Commons Attribution license (http://creativecommons.org/licenses/by/3.0/). 